Center of Business and Economics (WWZ), University of Basel

\title{
A Review on Energy Consumption from a Socio-Economic Perspective: Reduction through Energy Efficiency and Beyond
}


Corresponding author:

\section{Hannes Weigt}

Forschungsstelle Nachhaltige Energie- und Wasserversorgung

Wirtschaftswissenschaftliche Fakultät der Universität Basel

Peter Merian-Weg 6

Postfach, CH-4002 Basel

Tel. +41 (0)612673259

Fax +41(0)612670496

hannes.weigt@unibas.ch

A publication of the Center of Business and Economics (WWZ), University of Basel.

(C) WWZ 2013 and the authors. Reproduction for other purposes than the personal use needs the permission of the authors.

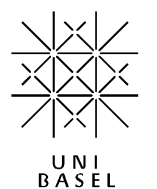




\title{
A Review on Energy Consumption from a Socio-Economic Perspective: Reduction through Energy Efficiency and Beyond ${ }^{1}$
}

\author{
Stephan Schmidt and Hannes Weigt
}

Corresponding author:

Hannes Weigt

Forschungsstelle Nachhaltige Energie- und Wasserversorgung

Wirtschaftswissenschaftliche Fakultät der Universität Basel

Peter Merian-Weg 6

Postfach, CH-4002 Basel

Tel: $\quad+41(0) 612673259$

Fax: $\quad+41(0) 612670496$

Mail: hannes.weigt@unibas.ch

\section{Abstract:}

Reducing energy demand and increasing energy efficiency are seen as major elements of the ongoing transformation of energy systems in multiple national and international programs like the EU 20-20-20 targets. Despite the predominately socio-economic nature of energy demand such interdisciplinary viewpoints - albeit on the rise - are still the minority within energy related research. In this paper we provide a review on energy demand both from an economics and a social science perspective. In particular, we aim to identify potential fields for combined socio-economic research efforts oriented at three questions: 'What drives energy demand?', 'Why do consumers behave the way they do?' and finally ‘How can (end user) energy consumption be influenced?’.

Keywords: energy consumption, energy efficiency, energy conservation, economics, sociology, political science

\footnotetext{
${ }^{1}$ We would like to thank Valéry Bezençon, Paul Burger, Mehdi Farsi and Ingmar Schlecht for helpful comments and suggestions.
} 


\section{Introduction}

Given the ongoing debate about climate change and further negative external environmental effects and risks of fossil and nuclear based energy provision a transformation of our energy system towards a sustainable path is a necessity. However, what exactly constitutes a 'sustainable energy system' and the speed of the transformation process are not generally agreed upon; e.g. following the setup of the Swiss Academies of Sciences (2012) a sustainable energy system should be oriented at the wellbeing of the individual and society while ensuring supply security, accounting for ecological and system inherent risks, as well as addressing economic efficiency. Due to the large uncertainties involved, the transformation process should allow for flexibility and the resulting system should have an inherent diversity.

While we do not want to address the detailed discussion on the definition of a sustainable energy system, it is obvious that this transformation process includes technological, economic, social and ecological factors and requires measures and instruments on institutional as well as individual level (Jackson, 2006). Taking the ongoing processes as benchmark this comprises i.e. a shift towards renewable energy sources and emission reduction in electricity production and heating, more flexible and 'smart' transmission and distribution systems, a transition of mobility options and management, energetically optimized buildings and a decoupling of energy demand and economic growth. In this context primarily technological aspects are in discussion based on the argument that technological innovation has the largest potential in terms of reaching the postulated transformation goals.

Despite the fact that technological improvements are a necessary fundament for the transformation of the energy system, a focus on technology is not sufficient and the consideration of social and economic factors is needed for a successful transformation. While one can argue that the production and transportation stage of energy supply are indeed driven largely by techno-economic topics whereas social factors like acceptance play a minor role, the reverse is true for the energy demand side of the value chain. To achieve a demand reduction via energy saving, energy efficiency and potentially sufficiency, consumers and their decisions and actions need to be taken into account. Although engineering aspects are important too, as energy saving applications and tools need to be developed, they do not seem to be the limiting factor in harvesting the benefits of energy efficiency: energy efficient light bulbs, thermal insulation or energy saving applications could be applied on a larger scale than currently observed. This issue is often described as energy paradox or energy efficiency gap and indicates that there seems to be a difference between the techno-economic optimal level and the observed level of energy efficiency usage. This paradox is rooted in the market and demand side and therefore requires a socio-economic perspective.

Although the energy demand side is dominated by socio-economic aspects, so far most research is either centered on economic or social topics. Consequently, the objective of this paper is to first provide an overview from an economic and social science perspective on the reduction of the energy demand through efficiency and beyond and to highlight the approaches of those two fields, respectively. Following we will highlight potential joint research fields distinguished into three rough 
topical clusters guided by three questions: What drives energy demand?', 'Why do consumers behave the way they do?' and finally 'How can (end user) energy consumption be influenced?'.

Given the diversity of economic approaches and the broad field of social sciences in general we will refer to the following distinctions for this review. We limit the individual economic perspective to classic market and price based approaches and policies, focused on how to achieve a specific (optimal) level of energy consumption, while fields like behavioral economics or political economy are considered socio-economic approaches. Similarly, the individual social science perspective is focused on political sciences and sociology, concentrating on the examination of rules, actions and decision patterns as well as structures and strategies regarding the demand of energy services, while aspects of psychology etc. are taken up in the combined socio-economic research fields. Given this outlet it becomes obvious that there is a high potential for interdisciplinary research. As will be shown in the definition of joint research fields there already are several approaches and collaboration beyond classical disciplinary boundaries.

To avoid further confusion, our understanding of joint interdisciplinary research does not refer to a common theoretic framework that needs to be endorsed by economists and social scientist but to topic specific collaborations. There are and most likely always will be lines of reasoning in the fields that are hard if not impossible to be merged. However, those aspects should not limit research in joint fields where the diverse disciplines can profit from the insights gained in other disciplines. Due to the high linkage of economic, social and political aspects addressing both the individual consumer and the society as a whole the field of energy demand provides a perfect field for such collaborations.

The remainder of this paper is structured as follows. In Section 2 basic definitions relevant for energy efficiency and reduction are provided. Section 3 presents the market based economic perspective focused on policy solutions for energy efficiency, whereas section 4 reflects the social perspective on efficiency and beyond. Section 5 then provides a review on potential fields and approaches for joint socio-economic collaborations. Section 6 gives a summary and conclusion regarding the main aspects of the review.

\section{Basic Definitions}

Although social and economic researchers have a different perspective on energy demand issues there are a number of general premises which we will shortly define as basis for this paper. The individual definitions and relevant aspects of the two disciplines that partly differ and are partly complementary will be provided in the subsequent sections respectively.

The most relevant basic definitions are the energy efficiency related terminologies: on a more technical level energy efficiency is typically understood as the amount of service per unit of energy input (Gillingham et al., 2009) which is the reverse of the energy intensity of a product or service. However, the term is sometimes also used to refer to energy efficiency improvements (Linares and Labandeira, 2010) and thus already incorporates an increase of the efficiency. Similarly, Savitz (2009) 
refers to energy efficiency "as the achievement of at least the same output of goods and services (at the same or lower cost) while using less energy.” In this context efficiency means that for the same process or the same output a smaller amount of energy or electricity is needed without referring to behavioral changes (e.g., both incandescent and compact fluorescent lamp have a specific energy efficiency, but often the switch from the former to the latter is meant in the context of energy efficiency).

On the other hand, energy conservation refers to the actual reduction in energy consumption of a specific activity compared to a benchmark. Whether this reduction is induced by an increase in energy efficiency or by other measures is not defined by the term conservation. However, energy conservation can also refer to the reduction in the level of activity itself (Dusyk et al., 2009). Similarly, if energy consumption is reduced without efficiency improvement one can use the label energy sufficiency which includes mainly behaviorally induced changes that reduce the energy demand (e.g., taking the stairs instead of the elevator). From a social science perspective sufficiency does not inevitably mean sacrifice or renunciation, but the directed and informed decision in favor of or against possible action opportunities and points to the change of preferences or changed frame conditions (Linz, 2006). For this paper we will refer to the basic technical definition of energy efficiency, differentiate conservation and sufficiency, and consider sufficiency as a process of informed decisions leading to behavioral change.

The reason for specific research on energy efficiency stems from the fact that energy efficiency improvements and applications are often regarded as being underutilized compared to the achievable cost savings of existing solutions. This energy efficiency gap or energy paradox is often attributed to several barriers and problems specific for energy efficiency, general energy market issues, overall market imperfections and behavior and social aspects. However, there is no generally agreed size of the gap as depending on the focus the 'optimal' level of energy efficiency can vary. Jaffe and Stavins (1994) indicate several levels of potential energy efficiency with specific gaps referring to differences between those levels (Figure 1). They differentiate between different potentials stemming from the elimination of market failures and barriers up to a hypothetical level of efficiency in which all influencing elements are removed. On the other side they estimate the obtainable "social optima" of efficiency by accounting for the necessary costs related to the removed market failures and barriers. They assume that the achievable optima are rather low compared to the theoretical efficiency levels due to the costs associated with policy implementation. Allcott and Greenstone (2012) argue that the common assessment of the gap is based on engineering analyses (e.g. like the techno-economic potential in Figure 1) and empirical estimation of the prevailing investment inefficiencies tend to be much smaller than estimated by those engineering analyses.

Jaffe and Stavins (1994) also point out that the diffusion of new technologies is not instant but typically follows a gradual pattern with slow adoption in the beginning, a fast shift later on, and a gradual slow down again once the implementation reaches a saturation level. Accordingly, the energy gap can be seen as whether the observed diffusion of energy efficiency is slower than what would be 
expected instead of just fixed levels. The hypothetical counterfactual of energy efficiency (diffusion) that should be observed with given technology and cost levels varies with the underlying assumptions which barriers and failures exist and to what extent they limit the utilization and implementation of efficiency enhancing technologies and behavior.

Wilson and Dowlatabadi (2007) are especially concerned to strengthen the social science aspects within the predominantly economics driven debate on the energy efficiency gap. They first emphasize that many of the market and 'nonmarket' failures relate to individual decision-making and are aspects of human behavior. These include e.g. aversion to risk, uncertainty, and irreversibility as well as heterogeneity of preferences within a population and sensitivity to changes in the attributes of energy. Second, in line with Allcott and Greenstone (2012) they point to the problem that the conventional framing of the energy efficiency gap is short-sighted. It allows the problem to be defined technically and be resolved by targeting individuals with universally applicable technologies, practices, and standards, but it overlooks the embeddedness of decisions regarding energy efficiency and the constraints on choice within the value chain of energy services. Thus, Wilson and Dowlatabadi favor a socio-technical regime approach - a structured web of interrelationships between social norms, human behavior, and technological systems - to properly explain the energy efficiency gap.

\section{Figure 1: The energy paradox}

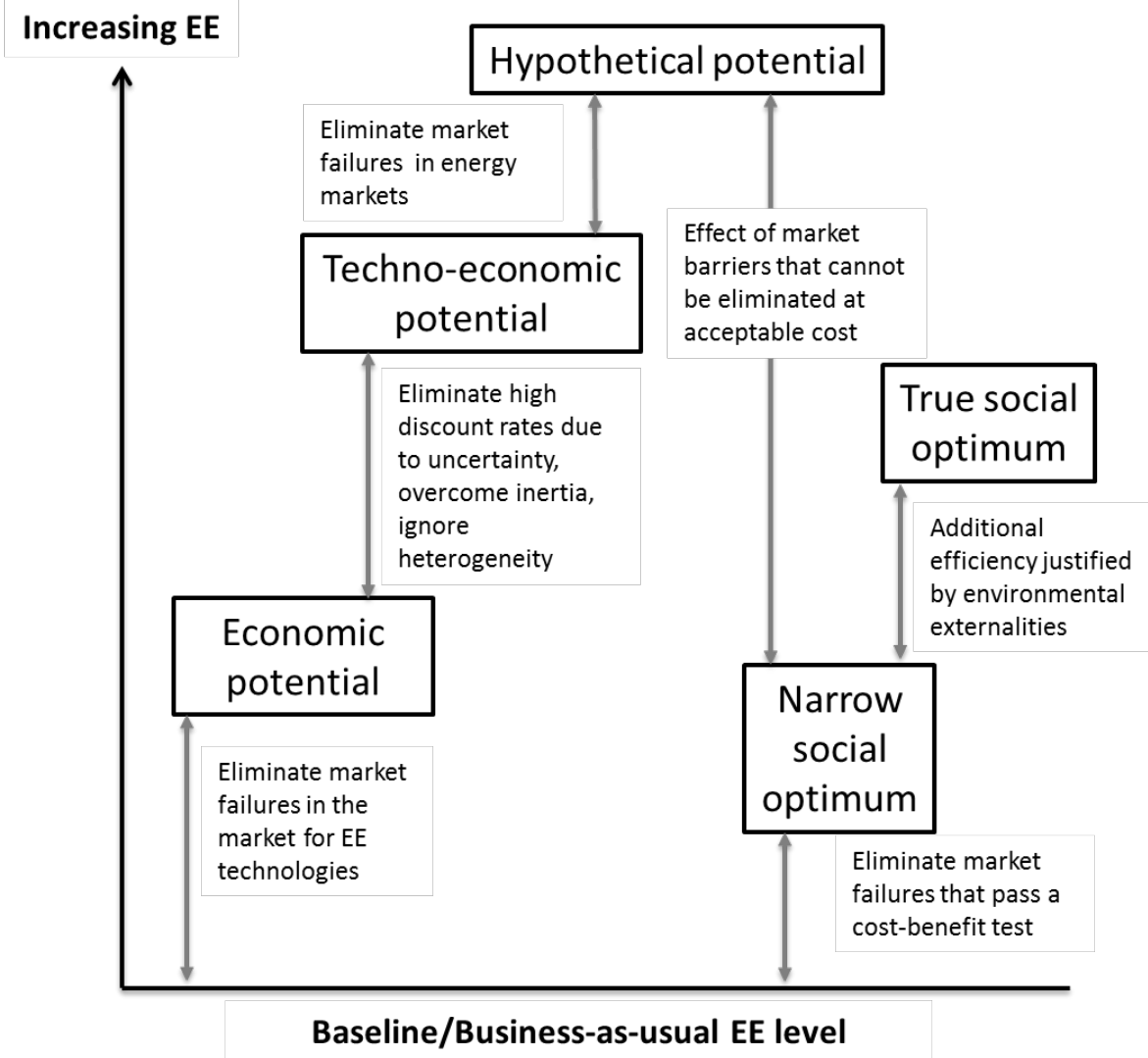

Source: based on Jaffe and Stavins (1994) 


\section{Energy Efficiency from an Economic Perspective}

As stated in Section 2 the economic perspective is centered on the energy efficiency gap. More general demand topics like demand-side-management or basic demand elasticity estimations are related but not the focus of the following section. Furthermore, approaches to enhance the understanding of (economic) decision making on the consumer side are considered socio-economic topics within Section 5.

The market and price based economic discussion is typically clustered in two blocks. On the one hand the gap itself is analyzed and potential causes are identified relying on basic economic principles like external effects, demand elasticity, and market imperfections. On the other hand potential policy options are discussed which are often linked to more general energy and environmental policy issues like climate change and renewable support. In this section we will summarize the discussed aspects in the economic literature regarding both reasons for the gap and economic policy options to address the gap. $^{2}$

\subsection{Reasons for the Energy Efficiency Gap}

The existence of the gap is normally attributed to a multitude of different aspects ranging from direct energy efficiency related issues to more general market barriers and failures and behavioral elements. In the following section we provide a brief overview on the most commonly cited aspects from an economic perspective.

\section{Energy efficiency related aspects}

One of the most common aspects related to energy efficiency is the so-called rebound effect. It indicates that an improvement of the energy efficiency does not lead to a similar energy demand reduction. The explanation for the rebound effect is typically threefold (e.g., Herring and Roy, 2007):

1. Direct effect (price effect): increasing energy efficiency leads to a reduction of the underlying costs and therefore increases the demand for the good/service if the demand is elastic

2. Indirect effect (income effect): reduced energy costs lead to a higher income share that can be spent for other goods and services which also require energy for their provision

3. Economy wide effect (macroeconomic effect): substitution, price and income effects lead to changes in the usage of goods throughout the economy which can increase energy consumption in other sectors, efficiency increases can also cause economic growth, and technology changes can lead to changes in consumer preferences

The rebound effect is typically measured as percentage of the theoretical demand reduction due to an efficiency increase. Thus a rebound effect of $0 \%$ indicates that all efficiency improvements are translated into energy demand reduction whereas a value above $100 \%$ indicates that actually more energy is consumed after the efficiency increasing activity. The latter is referred to as backfire effect.

\footnotetext{
2 This overview is largely based on Brown (2001), Dennis (2006), Gillingham et al. (2009), Jaffe et al. (2004), Linares and Labandeira (2010), Sanstad and Howarth (1994), and Tietenberg (2009), and follows a similar outlet as those papers.
} 
The impact of the rebound effect is subject to debate and varies greatly for different energy utilizations but in general seems to be below $100 \%$. Most of the debate on the rebound effect is not on its functionality but on its actual magnitude (van den Bergh, 2011). Greening et al. (2000) and Sorrell et al. (2009) summarize studies estimating the rebound effect concluding that the most likely range is somewhere between 0 and 30\%. These values indicate that the energy saving resulting from efficiency improvements is still significantly positive but can lead to higher expanses in reaching specific saving values and need to be accounted when designing energy policies.

A second aspect that is directly related to energy efficiency is the fact that there are only incomplete markets for energy efficiency. This refers to the problem that efficiency is often only an additional feature of a product and cannot be purchased separately, e.g. the fuel requirements of cars are only one of many features and typically one cannot order a more efficient car while keeping all other features. This bundling of efficiency with other features may be caused by the low energy prices and the resulting lack of interest of consumers (IEA, 2007). Increasing energy costs or a higher consumer awareness can lead to products specific for energy efficiency, like stand-by turn off applications or electricity demand monitoring.

\section{Energy market aspects}

As energy efficiency is typically pursued to achieve a cost reduction, energy prices play a major role in setting incentives for efficiency improvements. Consequently aspects related to energy markets have an important influence on efficiency.

With the focus on climate change aspects the missing representation of negative externalities in energy prices is a major concern. If environmental externalities like global warming but also classical pollutants like nitrous oxides and sulfur dioxide or local environmental damage due to resource extraction are not properly accounted for, energy prices are too low and the resulting energy efficiency will also be too low.

Beside externalities there are many other price deterring aspects in energy markets that can lead to distorted prices. Particular for electricity markets, average costs pricing can lead to over- and underutilization of energy. Most end user of electricity face a fixed charge independent of the time of use. However, during peak load conditions the marginal costs of electricity generation can be significantly above and during off-peak hours below this average. Particularly the peak load shading effects of real time pricing can have significant investment implications for power generation whereas the total energy demand effect is less clear. ${ }^{3}$

Also security externalities in energy markets are suggested as price distorting aspect (Bohi and Toman 1996). The argumentation is that in order to secure the stable supply of fossil fuels from unstable political regions the government has expanses that are not included in the price of the fossil fuels. Jaffe et al. (2004) point out that it seems unlikely that a marginal demand reduction would lead to a change

\footnotetext{
${ }^{3}$ For more information on real time pricing see e.g. Wolak (2006, 2011), Joskow and Tirole (2006) and Allcott (2009).
} 
in those expenditures whereas Gillingham et al. (2009) remark that long term reduction may reduce the associated risk and therefore not reflecting those costs will lead to an underinvestment in energy efficiency.

\section{Innovation aspects}

New technologies never replace all existing old technologies instantaneous but a slow diffusion process takes place. This is neither a market failure nor a barrier but the usual development of innovation and therefore also relevant for energy efficiency. Jaffe et al. (2004) show that this diffusion typically follows an S-shaped path due to differences in the characteristics of users and potential adopters. Furthermore the longevity of many energy related investments in the order of decades leads to a corresponding investment pattern. Naturally, the energy efficiency diffusion is largely influenced by energy prices but studies show that the adoption is more sensitive to upfront costs than to the expected energy costs, which has significant implications for policy design (Jaffe et al., 2004).

Market failures related to innovation diffusion are positive externalities in the form of $\boldsymbol{R} \& \boldsymbol{D}$ spillovers. Similar to not accounted negative externalities in energy markets that lead to too low energy prices not accounted positive externalities in innovation can lead to underinvestment in innovation and new technologies. Innovation leads to knowledge spillovers for other competing firms and reduces their costs of implementing the innovation. As the innovating firm does not profit from those benefits it will limit its R\&D activity accordingly. This is a general issue of innovation which leads to a higher social rate of return compared to the private rate (Gillingham et al., 2009). Furthermore, the interaction of market failures at the energy and environmental level with the technology innovation market failures increases the hurdles for energy policy (Popp et al., 2010).

A second potential spillover effect is related to learning-by-doing in the production and usage process. Typically, production costs tend to decline the more output is produced and experience is gained. If learning effects of one company spill over to other companies they lower the production costs of potential competitors. This reduces the incentives to engage in the learning process in the first place. Learning is typically expressed by the learning rate indicating the cost reduction in percentage points if the cumulative installed capacity is doubled. Values of $15-20 \%$ are common estimates but most studies deal with technological change in environmental technologies or power generation and not directly energy efficiency improvements (Popp et al., 2010). Learning effects are also difficult to distinguish from other cost reducing effects (Gillingham et al., 2009).

\section{Financing and investment aspects}

Given that energy efficiency improvements often require investments, uncertainty of future developments plays a major role. In addition investments in energy efficiency can be irreversible and not be recovered if improvements or price developments don't materialize as expected. This is a common issue in many investment decisions and is typically not regarded as a market failure per se (Pindyck, 1991). 
The high volatility of energy prices thus can contribute to a slow efficiency diffusion. If the option to delay the investment exists and energy prices are expected to increase while technology costs decrease the required return on investment can be significantly higher than under classical static net-present value estimations and therefore delay investments in energy efficiency (Jaffe et al., 2004). Related to this issue is the problem of overestimation of savings, unexpected higher investment costs or hidden costs. This can be caused e.g. by transaction costs (Joskow and Marron, 1992), not accounting for rebound effects, or a lower level of energy service (Linares and Labandeira, 2010); e.g. studies show that realized savings from utility-sponsored programs are about 50-80\% of the expected savings (Jaffe et al., 2004).

Another important factor for energy efficiency investments is the limited availability of capital and resulting liquidity constraints. Typically investments in efficiency have higher up-front costs and compensate by lower costs during operation. If the expected return of the investment is high enough the costs can be covered by a loan. However, it can be complicated to get the desired loan at conditions that make the investment economic (Tietenberg, 2009). This can be caused by the financing institutions restrictions e.g. due to the uncertainty of the investment, the lack of experience with new technologies, or the availability of other more profitable financing options for the bank. Similar limitations can exist on the company side and increase the necessary rate of return; e.g. budget limitations, separations between capital and operating budgets, or higher hurdle rates for non-core business activities (Linares and Labandeira, 2010). And for end users the financial standing may limit efficiency improvements to investments that can be paid without a loan financing. Uncertainties regarding financing like developments of interest rates can also limit the incentives to invest in (often long term) energy saving options.

\section{Information aspects}

Information problems are among the main reasons cited for the energy efficiency gap (Gillingham et al., 2009). The first information related problem is the sheer lack of information or hidden information. This can be related to the hidden cost and uncertainty problems. Consumers often lack the necessary information to compare different options or are unwilling to invest the time to obtain that information (transaction cost problem). Furthermore, many benefits only occur during the actual operation process and are hard to evaluate up-front. Fast technological progress may also make learning about those technologies less attractive as the gained experience depreciates (Tietenberg, 2009).

Also the public good characteristic and the positive externalities of knowledge can cause problems as already highlighted in the innovation aspects. The acquisition of information how to adopt new technologies can spill over to other users without compensation. Therefore, the adoption may not be carried out in the first place leading to missing information on the profitability and underinvestment in energy saving (Jaffe et al., 2004).

A further related problem is that many contractual settings are prone to asymmetric information and split incentives and lead to classical principal-agent problems. For example sellers know about the 
performance of their products and have to transfer this information to potential customers. However, as the sellers have incentives to overstate the efficiency, consumers may choose to ignore this information right away. Another typical setting with split incentives is the landlord-tenant example. Normally the landlord is responsible for the energy infrastructure investment whereas the tenant has to pay for the energy usage. Whereas the latter has an incentive to invest in energy saving technology but not the possibility the former has the possibly but no incentive to do so. IEA (2007) provides an overview about the most relevant principal-agent settings in the energy efficiency context and presents empirical evidence. The separated responsibilities within a principal agent setting may also limit the adoption of energy savings within a company, e.g. if capital financing and operation are separately organized (Tietenberg, 2009).

\section{Behavioral aspect}

As consumer choices are central for many energy efficiency aspects the so called behavioral 'failures' that summarize deviations from the theoretical perfectly rational assumptions underlying most economic settings are a further explanation for the gap. Gillingham et al. (2009) specify approaches in the context of energy efficiency and also provide empirical estimates. Naturally, those behavioral aspects are the center of behavioral economics and provide a valid field for joint socio-economic approaches (see Section 5). Following we shortly present the three explanations provided in Gillingham et al. (2009) that are also highly relevant for market based assessments.

Bounded rationality is closely related to the aforementioned information problems and assumes that consumers are rational in their decisions but are restricted in the amount of information they account in their decisions either due to limited time, limited available information or cognitive limitations of information processing. Consequently the resulting consumption choices represent the optimal outcome under those constraints but may not be the global or social optima given all available options. In a similar direction the theory of heuristic decision-making assumes that consumers either use decision strategies that do not follow the classical utility maximization or apply specific rules to reduce the choice options; e.g. focusing only on specific brands or eliminating specific products in a sequential decision making process (Tversky, 1972).

A third approach related to energy saving is prospect theory proposing that decision under uncertainty are always evaluated to a benchmark, often the status quo, and losses and gains are evaluated differently in this context. According to Shorgen and Taylor (2008) this can lead to loss aversion and a status quo bias which may result in non-rational choices.

Gillingham et al. (2009) state that the existing empirical literate on the combination of behavioral aspects and energy efficiency is limited but hints on a systematic bias in consumers' decision-making with respect to overuse of energy and underinvestment in efficiency.

\section{Other aspects}

There are many further aspects influencing consumer decisions, market efficiency and policy choices. One of the major influencing element regarding all social economic choices and therefore also relevant 
in the energy context is the divergence between the social and private discount rate. Jaffe et al. (2004) state that the implicit discount rates in an energy saving context are in the range of $20 \%$ to over $100 \%$ which is significant higher than normal private discount rates. These high rates are a potential reason for an energy gap if the hypothetical efficiency level assumes a lower discount rate. Furthermore, there is an ongoing debate about the social discount rate and whether a divergence between private investment and a social desired level of investment merits a justification for policy intervention.

A second relevant aspect in the energy context is the consumer heterogeneity and the resulting differences in energy usage. If estimates of optimal efficiency levels are based on average consumption patterns and assumptions there will always be a fraction of consumers for which those investments are not attractive. Also the reaction to energy policies or price changes can be different for different consumers (Reiss and White, 2005).

\subsection{Common Policy Solutions from an Economic Perspective}

Given the multitude of aspects that can cause the deviation between realized and desired energy efficiency it is not surprising that there are also many different policy approaches to address those issues. Following basic economic guidelines only those aspects that can be classified as market failure should be addressed with market interventions. But as Linares and Labandeira (2010) point out there is also support for a wider approach addressing non-market failure issues via energy policy as well. Following the main policy elements addressing the above described economic aspects of the energy efficiency gap are shortly presented.

\section{Internalizing energy market externalities}

One of the main reasons for the low level of efficiency is the low energy price which is partly caused by insufficient consideration of external effects. Thus any energy policy that addresses those issues will also have an effect on the profitability of energy efficiency. However, the objective of those policy approaches should not be to increase efficiency but to target the initial problem. For climate change and environmental aspects taxes or cap and trade systems like the European Emissions Trading System (EU ETS) are classical policy tools; for security issues import tariffs can be used (Tietenberg, 2009). As those approaches will lead to higher energy prices the incentives to increase energy efficiency will also rise.

\section{Innovation policy}

Innovation is also a broad policy field that can have a significant impact on energy efficiency. Patents and licensing restrictions and regulations are major influences on R\&D activities of companies and technology diffusion in general. Whereas patents typically encourage innovation they often have a negative effect on the diffusion as they result in temporal monopolies (OECD, 2004). Common approaches to address the public good aspects of knowledge and innovation are governmental support schemes for R\&D and public-private research co-operations (Brown, 2001). Similarly, subsidies for education and training are a tool to reduce company costs of R\&D. Regarding the diffusion of 
technologies the government can encourage the adoption again via subsidies and tax credits reducing the purchase prices or directly apply new technologies in its own offices and institutions and thereby increase demand for the products (Jaffe et al., 2005)

\section{Direct energy efficiency support policies}

The policy options to directly address energy efficiency and support energy saving behavior are similar to classical environmental and industrial policy settings. The applied instruments can be clustered into command and control instruments and market based policies. Within the first group especially technological and product standards can be used to incentivize a higher efficiency level within the economy. Given the ease of implementation and their effectiveness in reaching specific targets they are a popular policy choice (Linares and Labandeira, 2010). However, as most command and control instruments they lack in economic efficiency as they don't lead to an equalization of efficiency costs across industries or consumers (e.g. see Perman et al. 2006).

Contrary, market based instruments typically achieve a cost efficient outcome but often are more complex to implement. Taxes are the basic price signal policy option. Given perfect information taxes can theoretically ensure an optimal market outcome by obtaining equality of marginal costs and marginal benefits. However, given the typical lack of precise (social) cost estimates and demand functions the optimal tax level is not known ex-ante. Furthermore, subsequent adjustment processes of taxes, particularly raising too low taxes, often faces opposition from affected parties. Similarly, the resulting demand reduction is not known ex-ante and therefore taxes are typically limited in their effectiveness in reaching specific quantity targets. Subsidies and other financial support schemes can be regarded as negative taxes and typically provide incentives to improve energy efficiency (e.g., insulation or new appliances). Gillingham et al. (2009) provide empirical studies on the effectiveness of financial incentives stating a rather mixed outcome. A major difference between taxes and subsidies is the related budget impact. While taxes provide revenue for the government that can be utilized for further efficiency related investments, subsidies require input from the governmental budget. The situation for the tax payer/subsidy recipient is the other way round. Subsidies are furthermore subject to the free riding problem: if governmental funds are spent on efficiency improvements a part of the carried out investments would have occurred anyway. This reduces the impact of the contributed budget and thereby reduce overall economic efficiency.

Further common policy tools are cap and trade systems. In the energy efficiency context these are typically referred to as white certificates. Similar to a green quota system an overall efficiency target is defined that energy consumers need to comply with by handing in a corresponding number of certificates which can be either achieved through specific energy saving activities or via trading from other parties. Contrary to taxes the certificate scheme are quantity based and therefore effective in reaching a desired demand reduction target. In addition, due to the trade possibility costs between agents are equalized thereby leading to a cost effective solution. 


\section{Information and behavioral policies}

As information and behavioral aspects play a major role in energy demand reduction, programs to overcome those the related barriers have become a common supplemental instrument. The main aim of information programs is to reduce transaction costs, provide reliable information and eliminate inefficient choices (Tietenberg, 2009). Information related policies are often an element of demandside-management programs (Gillingham et al., 2009). However, the actual applied instruments can vary greatly. A typical policy is labeling: either governmental or independent organizations provide certified labels on products or property regarding its energy consumption to provide an easy option for comparison. Naturally, these policy approaches move in the direction of what we term as socioeconomic approaches as they link individual decision making with market approaches.

A mix of information policy and command and control are so called smart meters. On the one hand they are often implemented via mandatory installation guidelines and thereby are similar to technological standards. However, there main objective is to provide more and easier accessible information to consumers and/or suppliers.

\section{Combined Policies}

Following the Tinbergen rule (Tinbergen 1952) each policy objective should be addressed with an individual instrument. Given that energy efficiency is causes by a multitude of barriers and failures that are furthermore interlinked with more general energy and environmental policy aspects addressing each of those with individual instruments automatically leads to a highly complex system. ${ }^{4}$ Although, studies explicitly addressing efficiency polices are scare so far, existing studies and experiences from more general energy policies show the importance of this aspect. I.e. the interaction of energy efficiency and renewable policy is analyzed by Harmsen et al. (2011) and del Río (2010). They show that a RES quota system can profit from additional efficiency measures as they tend to reduce the overall demand level and thereby the absolute level of needed RES investments. Meran and Wittmann (2012) show that a combination of emission, renewable, and efficiency quotas lead to inefficiencies and higher abatement costs.

Summarizing, the economic perspective on energy efficiency aims to improve the market performance by addressing market failures and barriers by specific policy measures. The overall objective is to reduce the gap between observed efficiency levels and theoretically obtainable levels. The consumer perspective and especially consumer behavior gains importance in this analysis but is not yet the main focus. Besides the presented general picture there is also a multitude of economic studies addressing specific, singular topics, markets and countries; e.g. estimating rebound effects of specific sectors, quantifying correlations between energy demand and economic growth, or analyzing the design of specific policy measures.

\footnotetext{
${ }^{4}$ Fischer and Preonas (2010) and Gonzales (2007) provide a review on interacting energy and environmental policies.
} 


\section{Energy Consumption Approaches from a Social Science Perspective}

The social science perspective focused on political sciences and sociology aims to highlight the connection between human activities its structures and evolving strategies and primary energy demand. This relation is identified as a crucial aspect in exploiting the potential of the reduction of energy use. In general, consumption can be seen as the part of human activity that converts material or spends energy (Daly, 1996). Korsunova (2010) states in this regard that energy consumption is a basic need and an imperative condition for being, and likewise energy consumption is unavoidable. However, it is possible to adopt a strategy of reduction in energy consumption in order to move towards a sustainable energy system. Attempts to understand consumption behavior in general can be distinguished into two domains. One sphere relates consumer behavior to the context and infrastructure emphasizing physical assets, taxation and pricing policies, technological as well as societal innovations etc. A second domain reduces consumer behavior to be the end of psychological and social drivers. But as Mont and Power (2009) state correctly, neither of these approaches is sufficient in isolation. Heading for a holistic perspective in order to understand how various political, technical, social and economic drivers overlap and influence each other, a more thorough understanding of these complex factors will facilitate the development of more effective policy solutions (Mont and Power, 2009).

"Aggregated actions of individuals and organizations determine many aspects of the energy system, with demands on the system and the balance of supply and demand affected as much by individual choice, preference, and behavior, as by technical performance” (DOE, 2011). As mentioned in the first paragraph social factors getting the center stage in the context of an energy consumption reduction. In this sense the energy system can be considered as socio-technical system focusing on operating conditions, actor dependencies and organizational aspects (Jonsson et al., 2011). The social science perspective on the reduction of the energy consumption underlines the necessity of a societal and structural change including lifestyles, consumption and values (Dusyk et al., 2009). Hereby the agency of the user gets an important meaning. Following Ortner (1999) agency is the capability to be the source of actions. "Agency is related to [...] self-determination, authentic self-direction, autonomy and so on. The concern for agency means that participation, public date, democratic practice, and empowerment are to be fostered“ (Alkire, 2005, p. 3). The general debate on agency is rooted in questions of social structures, individual power, routines or norms and cultural practices. Regarding energy consumption and efficiency, research approaches of agency differ between focusing on price, markets and information on the one hand (economic conceptualization) and emphasizing social and cultural factors on the other. The latter argues that agency lay with the idiosyncratic user, which means the user 'domesticates' technology (Wilhite, 2008). This opens the opportunity to integrate user attitudes, lifestyles and values as driver for the reduction of energy consumption. 
Mundaca et al. (2010) for example point to ,market and behavioral failures' representing the complex reasons, why the reduction and transformation faces some severe challenges. On the one hand institutional, legal and economic frame conditions are in question for the sake of the market dissemination of technological innovation. On the other hand not only rebound effects, but also societal developments overcompensate e.g. efficiency wins. This overcompensation is represented by but not limited to an increasing urban sprawl as well as by the trends of decreasing size of households or more living space per person (Schipper, 1996). Although many reduction potentials are identified and from today's technical point of view are exploitable the critical aspect refers primarily to questions of implementation. From a social science perspective with a focus on political sciences as well sociology there are some explanatory approaches to describe and analyze as well as some strategies to dissolve this situation. However, it is pretty obvious that only coupled efforts in efficiency and sufficiency can lead to successful reduction strategies. In this context Dusyk et al. (2009) argue that it becomes crucial "to move toward more transformative approaches that integrate energy efficiency and conservation with broader development path changes”. From an energy service perspective the central aspects in question are then: why is the service called upon; what type of services is needed; how can the service be delivered. Jonsson et al. (2011) further define energy services as „the functions and utilities by which a resource could, directly or indirectly, enable, facilitate or add value to human activities“. This means in most cases energy is not directly demanded, but energy services are asked for (Lerch, 1995).

\section{Behavioral aspects as determinants of the energy consumption}

Regarding human activities and primary energy demand - respectively the demanded energy services behavioral aspects can be identified as determinants. Energy-related behavior in this sense can be distinguished between investment and habitual behavior. The first points to the occasional purchase of new technological devices or in general adopting new technologies, whereas the latter is based on routines and practices in the daily energy consumption, such as switching off the computer after work. With regard to conventional (economic) approaches the starting point of research is the decision to purchase. But it is obvious that the combination of purchase and product-use decisions is crucial. Whereas in some cases the investment itself drives the resource use in other cases the patterns of use are more important (Princen, 2006). Gynther et al. (2011) argue in this context that 90\% of energyrelated behavior is habitual. However, the choice not to purchase or to seek less consumptive means of satisfying a need is relevant too, but only few research is done so far because it is difficult to analyze an act that entails not doing something (Princen, 2006). Regarding the habitual behavior, attitudes and contextual factors are getting central importance since these have a crucial influence on the automatic and routine behavior of the user. Gynther et al. (2011) further name on the one hand personal beliefs, norms, social identity as well as values as related to attitudes, and on the other hand monetary incentives and costs, physical capabilities and constraints, institutional and legal aspects as well as social norms as contextual. The contextual factors are in close relation to the term agency of the user. Both attitudes and contextual factors are determinants of energy-related behavior with impact on 
consumer choice addressed through predisposing factors that motivates behavior (e.g. awareness), enabling factors that facilitate behavior (e.g. external resources) or reinforcing factors (e.g. feedback from experts) (Gynther et al., 2011).

\section{Decision making related to energy consumption}

In the problem and definition part above we refer to the issue of asymmetric information and the principal-agent problem, which arises mainly between supply and demand. A common example in this sense is the relationship between energy utilities - especially in non-liberalized markets - on the supply side and the end consumer on the demand side. The latter is somehow embedded in the given frame conditions by the utilities regarding infrastructure, pricing or incentives to reduce energy consumption, hence dependent on the good will or business model of the utilities. The support of informed decision making of the demand side related to energy usage means to avoid this situation in terms of more transparency and informational openness. Making energy visible, market-based instruments like labeling and standard-setting are designed to help consumers make these informed choices. It also encourages producers to design more efficient appliances (Shove, 2006).

But following this rational choice model is a limited solution strategy: consumers have insufficient information to make proper choices, thus policy seek to improve access to information (Jackson, 2006). This idea leads to the question, if providing consumers with increased information actually allow people to make more-informed decisions? The limits of this strategy can be seen in informational overload of the consumers, which results in analytic paralysis and structural obstacles in adopting new ideas or innovations etc. However, providing clear information to the demand side is a necessary, but not a sufficient step to more informed decisions. As Jackson (2006) stated, consumer actions are not necessarily in line with the rational choice model. They do not always act benefit maximizing (or cost minimizing); actually they neither do always deliberate over costs nor benefits at all.

Households are facing different barriers including existing regulations, infrastructure issues, limited consumer choice, and a lack of information. To overcome these barriers it is necessary to combine behavioral interventions with policies aimed at facilitating their adoption. Households are focusing mainly "on available no-or-low-cost behavioral interventions that do not require a major lifestyle change, such as weatherizing houses or properly maintaining” (AMACAD, 2011). Energy policies often overlook this aspect and address only individual barriers. In this sense energy policies do not connect individual and collective issues and fail to gain attention on a societal level. Additionally, the mentioned price sensitivity of households is somehow wrongly interpreted by policy makers. Pyrko and Darby (2011) recommend in this sense that making more of the ,fixed charges“ proportional to actual consumption could give more of a signal to promote conservation, and be more equitable.

Regulators are asked for to better complement existing regulations requiring the use of certain energy efficiency strategies. This may allow the up-front costs of energy efficiency retrofits to be paid by third parties, who would then share the long-term savings in energy costs with the property owners. In other words the role of regulators has to be changed: "The historical function of regulators has been to 
decide whether projects proposed by utilities are prudent, reasonable, and necessary. Regulators must learn to be more proactive in clarifying the objectives of existing statutes and aligning stakeholder incentives with those objectives.” (AMACAD, 2011).

Third-party intermediaries are important multipliers able to spread and deliver information about potential activities regarding the reduction of the energy demand. In this sense e.g. realtors, mortgage providers, and service engineers can provide the essential aspects to current and prospective property owners targeting the reduction of energy demand. The third-party agents have to be educated as well as supported by awareness rising about their existence and the resulting benefits. A specifically promising situation to inform households about potential energy savings arises when those households undertake home renovations not related to energy.

\section{Processes of institutionalization and Governance}

Decisions of energy use are made decentralized by households, companies or public institutions, which makes the realization of efficiency as well as sufficiency potentials a complicated endeavor in terms of a highly differentiated process of societal organization. This realization is based on learning processes to be understood as a way of institutionalized strategies of doing things different and better. Exploring energy efficiency and sufficiency potentials in this regard means to model change rather than modeling energy use. Both, individual and collective action is a means and subject of this modeling process.

The critical factors to effect change in the given system constellations - i.e. destabilizing existing regimes and creating new ones - are: establishing coherent goals, introducing policy instruments that are consistent with these goals, and capacity development to ensure the adoption of governance strategies and policy tools (Dusyk et al., 2009). Hence, the crucial question is how the energy consumption can be influenced or steered by policy instruments and related tools. AMACAD (2011) emphasizes the benefit of polycentric governance to answer this question. It points to the simultaneous multiscalar operation of manifold policies as well as the participation and consideration of diverse stakeholders. It combines the benefits of local actions, i.e. fostering innovation and flexibility, and of federal activities offering economies of scale. Polycentric governance provides backup policy mechanisms that overcome resulting imperfections from intervention at a single level.

\section{Private consumption, the public, change of values and group norms}

The interplay between private consumption and the public is crucial regarding the reduction of the energy consumption. Private decisions and consumption patterns are embedded in the political steering of market and societal processes. For this reason Heidbrink and Reidel (2011) state that contradictionary public influences and situative constellations prevent the realization of given dispositions to act and favor misinterpretations of the private actors. Hence, policy instruments have to be created, which facilitate the implementation of the disposition to act. Heidbrink and Reidel (2011) naming three political strategies creating favorable conditions to reduce the energy consumption: to 
simplify ways (reduction of barriers), to impede wrong ways (set up barriers) and to facilitate new ways (promote innovations). This would help to embed private decisions in a favorable public frame. As stated above, sufficiency as a strategy for consumption reduction must not be conceived as an issue related only to individual decision-making. Such an 'individualization of responsibility' would overburden consumers (Linz, 2004). Thus, sufficiency is not only an individual concern and more to be captured as a social and political challenge. It comprises a need to develop circumstances in which individuals cannot only consume less but can substitute consumption for other processes.

One possible strategy to strengthen reduction patterns is to shift energy loads to public spaces where social norms may discourage excessive consumption by limiting "free rider" behavior. Cohen et al. (2010) emphasize the opportunity to exert social pressure to reduce energy consumption based on the expression of shared community values and goals. These values are grounded either in ecology, social cohesion and economic efficiency, or in personal fulfillment. In every case reducing energy consumption is called a necessary mean. Cohen et al. (2010) state that persistent social pressures for the reduction of the energy consumption, rooted in shared community values and identity, were found to be essential to a change in priorities and behavior, although our individualized society where social networks and institutions are not necessarily tied to specific locations hinder this linkage. The challenge for a society is to rebuild a similar place-based sense of community to allow the pursuit of reduction patterns as a collective good instead of just an individual choice.

Stengel (2011) favors a different way of effect changes in individual values and social norms. To offset barriers to adopt especially sufficiency strategies means to emphasize two opportunities: the first points to fostered cultural processes, which aim to reduce costs of the individual consumer exerting sufficient actions. The target here are the social norms the individual consumer is embedded in. Stengel argues that an alteration of the symbolic meaning of consumption patterns can lead to a change in interpretive structures and action frames acknowledged as standard of the target group (e.g. smoking cigarettes). The second opportunity focuses on individual norms, which are subject of a 'moral development' of the consumer striving for the extension of the willingness to bear the costs of sufficient actions. This changed sense of responsibility represents the basis of new action strategies, i.e. the gap between thinking and action can be bridged.

To sum up the social science perspective with a focus on political sciences and sociology aims to strengthen the consideration of the energy system as socio-technical system. Thus, the connection between human activities and primary energy demand and the embeddedness of decision-making has central meaning. A key challenge is represented by the examination of reasons, motivation and behavioral patterns regarding the demand of energy services. In this regard, the social science perspective argues then that following a rational choice model is a limited solution strategy, because consumer actions are not necessarily in line with this model.

Following the social sciences the crucial issue is the necessity of a societal and structural change including lifestyles, consumption and values to tackle the challenge of the reduction of the energy 
consumption. It requires coupled efforts in efficiency and sufficiency measures to lead to a successful reduction and thus, socio-economic approaches to prepare the path to a sustainable energy system.

\section{Joint Research Fields for a Combined Socio-Economic Perspective on Energy Consumption}

As is evident from the previous sections both the economic and social science view on the energy demand side are neither completely uniform nor completely opposed. Together they provide a mix of individual viewpoints, complementary approaches, and similarities. While the first point verifies singular research approaches the other two points provide a solid ground for interdisciplinary collaborations to benefit from the respective insights of the other field and thereby provide a more holistic approach to tackle the challenges at hand.

Both science and politics need to gain knowledge on how change of behavior in energy consumption can be realized. Existing research has been focused on studies on price sensitivity, drivers and barriers for accepting new technologies and rebound effects to the exclusion of other socio-cultural aspects (Gynther et al. 2011). The research on individual decisions on energy consumption is often narrowed to financial incentives and rational actor-models. What can be taken for granted in the context of the general energy consumption, is especially pressing regarding the question of so called gray energy consumption. As basically every product or service requires energy input at one stage of its value chain every consumer decision will have an energy impact. Consequently, if consumer decision patterns and behaviors are the subject of interventions one needs to address potential rebound effects (or possible positive multiplier effects) via embodied energy. This requires on the one hand a broader analysis of embodied energy values for a wide range of products and services and on the other hand a quantification of changes in product use and purchase.

Generally speaking, there is a lack of a robust comprehensive framework that captures the different aspects of individual energy behavior across the currently established categorical sets in economics and the social sciences. Hence, recently socio-economic endeavors and interdisciplinary concepts fragmentarily spanning from technological aspects over economics to psychology and social science are getting on the research agenda without establishing a common idea about designated research fields. Consequently, improvements are needed regarding a common research agenda and especially concerning the transfer into the political decision process. Following we will provide an overview on potential research fields that, based on the carried out review, can provide promising fields for interdisciplinary socio-economic collaboration and represent the requested research agenda. We distinguish three rough topical clusters following three important questions that from our point of view need to be answered to achieve progress in energy politics: What, Why, and How.

First, the question 'what drives energy demand' needs to be answered. This summarizes the full range of (techno)-socio-economic determinants and drivers of energy consumption with respect to observed/realized behavior. Those determinants need to be identified and quantified as they provide a 
relevant input for theory building and applications. Second, the question 'why do consumers behave this way' needs to be addressed. Whereas the 'what' only looks at the results the 'why' is concerned with the internal and external influences namely motivations, cognitive and affective factors, moral and social norms, and how they form the decision process. As consumers have the center stage in this field their behavior and decision making constitutes a core element of a combined socio-economic perspective. Finally, the insights from those two questions need to be combined to answer the last question of 'how (end user) energy consumption can be influenced'. If the political objective is to reduce resource and energy consumption a constitutive framework and recommendations for political intervention will be needed that goes beyond the current - apparently not sufficient - policy schemes. This provides a potential joint research area for topics addressing political economy, policy design and governance.

\section{1 'What': Socio-Economic Determinants of Energy Consumption}

A first step to address the challenge of reducing energy demand is to analyze the direct observable energy consumption patterns. Despite the fact that the reduction of household energy consumption is part of many international and national energy policies (e.g., European 20-20-20 targets, UK Energy Efficiency Strategy 2012, Swiss Energy Strategy 2050) surprisingly little is still known about what composes energy consumption beyond basic techno-economic aspects. Accordingly, it still has to be disclosed which relation exists between the context of energy consumption and the infrastructure of the same. Socio-economic research has to relate on the one hand physical assets, taxation and pricing policies and technological development with societal innovations and social drivers on the other hand. Understanding how various political, technical, social and economic drivers overlap and influence each other, a more thorough understanding of these complex factors will facilitate the development of more effective policy solutions.

Historically, energy demand has long been regarded as a fixed parameter that needs to be satisfied and consequently most research was focused on forecasting demand (developments) for the short and long run, i.e. the relation between economic growth and energy consumption (e.g., Coers and Sanders, 2013). With an increasing awareness of energy limitations and environmental concerns in the 80s and the liberalization processes in the European and US energy markets in the 90s the need for a better understanding about the economic properties of demand emerged (e.g., Lijesen 2007, Filippini 2011). For energy efficiency also the willingness to pay for specific energy saving investments has been analyzed (e.g., Banfi 2008). These research directions have in common that they focus on a classical price-quantity relationship which forms the basis of the economic reasoning presented above and a majority of economic market models.

In recent years there is an increasing interest in extending this analysis towards additional aspects determining energy consumption beyond the price-quantity dimension. These include studies that address non-economic, external driving factors e.g. political viewpoints (e.g., Kahn 2007, Costa and Kahn 2013), lifestyles in general (e.g., Bin and Dowlatabadi 2005, Sanquist et al. 2012), the 
combination of technical with behavioral/social factors (e.g., Yun and Steemers 2011, Kavousian et al. 2013, Wyatt 2013), and the awareness on energy consumption (e.g., Kang et al. 2012, Brounen et al. 2013). In addition there is a growing body of literature on embodied energy in different sectors; e.g. buildings (e.g., Cabeza et al. 2013), renewable energy production (e.g., Muench and Guenther 2013), or on general international trade (e.g., Wiedmann 2009). This topic naturally borders with live-cycle assessments and more general ecological footprint analyses. Furthermore, the internal motivation and decision process is tackled via experimental analyses and psychological studies (see Section 5.2).

Those extensions beyond the price-quantity relationship help to provide a more general perspective on energy consumption. Identifying which factors are the main drivers for consumer`s energy choices and, similarly important, which factors are not relevant in the energy context is a crucial element if consumer specific policies are to be successful. This requires an extension of the existing empirical literature both with regard to pure numbers to provide a more valid basis and with regard to noneconomic and combined socio-economic determinants. Whereas there are plenty ideas about potential drivers for energy consumption their quantification and assessment of significance is still lacking. To tackle this challenge both, economics and social science, will largely have to rely on statistical methods and (field) experiments to provide the necessary first insights. However, to be of value for the development of successful (policy) interventions those insights need to be transferred into a conceptual and if possible generalizable frame.

\section{2 'Why': Behavioral aspects and decision making}

The potential common research field regarding the 'Why' in the context of energy consumption deals with the internal and external influences namely motivations, cognitive and affective factors, moral and social norms, and how they form the decision process. Accordingly, consumer behavior can be seen as grounded on individual decisions, although these decisions are embedded in and dependent from supply-side measures, an appropriate infrastructure and social-political factors (Brohmann et al., 2009).

It has widely become common sense in energy related behavioral research that traditional models of consumption and decisions (e.g. consumer sovereignty; rational choice) are limited in its explanatory relevance. The model of bounded rationality for example states that limited capacities of processing information lead to rules of behavior and routines. In line with this, a number of recent studies have demonstrated the limitations of information-based instruments that are particularly popular with policy makers when attempting to address consumption-related impacts. Researchers have shown that when information-based instruments are used alone, they are rarely effective: knowledge does not directly lead to changes in attitudes, and attitudes in their turn are not always translated into behavior - the reality is far more complex (Mont and Power, 2009). Furthermore, a well established diversification is related to classical approaches of psychology (e.g. attitude-behavior models), which now involve more and more the role of participation, the social context and macro-level factors. Thus, as Kurz (2002) 
explains within the idea of a social-ecological framework, the individualistic perspective on decisions is broadened and contextualized which is crucial to explore energy related behavior.

Wilson and Dowlatabadi (2007) take up the question of energy related behavior and decision making and show in their proposed framework 'An integrated model of pro-environmental behavior' the relation between a) the personal and b) contextual sphere as well as c) between attitudes, habits, capabilities and external conditions as the underlying scheme to clarify 'why do consumers behave this way' (Figure 2). Within the different categories and variables of the framework the authors show starting points for common socio-economic research. They introduce opportunities to combine socioeconomic determinants on the one hand and psychological aspects as norms, beliefs and values on the other hand. This is reflecting a necessary step to analyze consumer behavior in a more holistic way by identifying economic as well as behavioral factors. This leads to an integration of public economics, marketing and social sciences.

Figure 2: Model of pro-environmental behavior

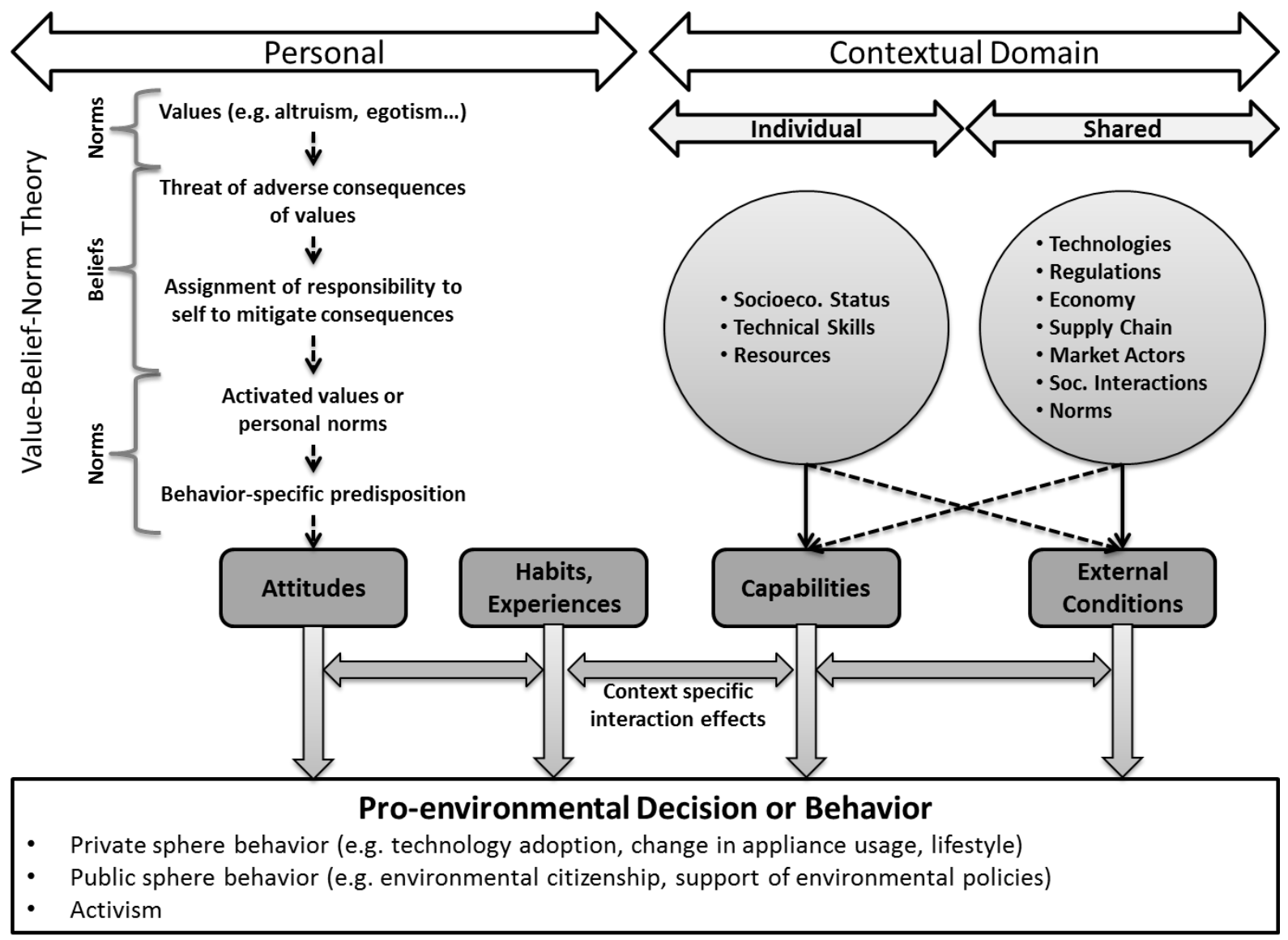

Source: based on Wilson and Dowlatabadi (2007)

Another, but yet rarely used approach to explain energy consumption behavior are lifestyles. Here, classical economic panel analysis together with a wider societal respectively social milieu analysis gives a conceived picture of the fragmentation in society and thus, opportunities to collaborate between economic and social sciences. A lifestyle is characterized by similar socio-demographic and socio-economic factors as well as by values, preferences and competencies resulting in specific 
behavioral patterns. Hence, lifestyles have a high potential to a) disclose energy related decision processes and b) to lay the ground for common socio-economic research endeavors. It describes societal structures and supports to explain the aggregation of individual behavior to common energy consumption patterns. Whereas Reusswig et al. (2003) show the high share of lifestyle related emissions especially for western countries in general, another strand of literature shows the differences between groups of lifestyles regarding the individual energy consumption (Birch et al. 2004; Wei et al. 2007; Weber and Perrels 2000; Lutzenhiser and Hackett 1993; Fong et al. 2007).

Another large field for linking social science, psychology and economics to analyze the driving forces behind consumer decisions are approaches applied within experimental and behavioral economics. As indicated in Section 3 there are several possible behavioral explanations for the existence of the energy efficiency gap. To understand their impact on energy demand thereby provides a promising research field for joint collaborations.

Obviously, the 'Why' question is closely related to the 'What' question in section 5.1 regarding the wide range of structural as well as individual aspects related to the energy consumption patterns. Whereas the determinants question is focused on identifying socioeconomic drivers and on understanding the interplay of the various political, technical, social and economic aspects, the decision making question is more referred to the clarification of the interlinkages between the personal variables and the socioeconomic determinants, respectively the influence of the latter on behavior and actions regarding the energy consumption patterns.

\section{3 'How': Policy design and governance}

While the socio-economic determinants and behavioral decision drivers help to better understand how the observed energy consumption emerges the crucial element to achieve a sustainable energy system will be the implementation of (policy) interventions to change this behavior. Consequently, also on this 'final' stage a combined socio-economic approach can be expected to provide a more comprehensive picture than single discipline approaches and hopefully provide better recommendations for interventions than the ones currently in place. But, as always with real world implementations, achieving satisfactory results on this field may be the hardest of the three potential common research fields.

As indicated by the review so far there is a difference in the understanding of the objective at stake. To derive potential fields for cross-disciplinary endeavors it can be helpful to start by mapping the problem in a systematic way that allows each field to contribute. This mapping can help to both identify areas for (policy) interventions and the relevant aspects (and thereby contributions by the different disciplines) that need to be accounted in these areas. Different frameworks to cover energy related aspects have already been developed that can act as a starting point. ${ }^{5}$ Stephenson et al. (2010) develop an Energy Cultures framework to derive a better understanding of consumer's energy

\footnotetext{
${ }^{5}$ Those concepts can equally be considered as frameworks to help understand consumer behavior and therefore are also relevant for the discussion in Section 5.2.
} 
behavior. The framework addresses the interaction between cognitive norms, the material culture and energy practices (Figure 2, left panel). Those three concepts are themselves interacting systems and are furthermore influenced by wider systematic aspects. Sweeny et al. (2013) extend this framework by an inner level covering the individual's motivation which is connected to the surrounding cultural level via barriers and supporting aspects. Stephenson et al. (2010) use this framework to identify areas for interventions in the household heating sector and Lawson and Williams (2012) for the clustering of energy consumers.

Another attempt to clarify different influences on behavior and identify potential points for action is the 'Diamond' framework emerging in the UK climate change mitigation discussion (Fudge and Peters, 2011). This framework is centered on four types of intervention - Enable, Engage, Exemplify and Encourage - that help to structure the multiple intervention options and link them towards consumer's behavior thereby extending the usual policy horizon (Figure 2, left panel). Contrary to the Energy Cultures framework the structure is directly aimed at intervention with the overall policy strategy addressing all four dimensions. Chai and Yeo (2012) propose a different conceptual framework based on a system approach. They develop a stage wise process to understand the adoption and implementation of energy efficiency practices starting with the basic motivation, followed by the capability to act, the implementation of projects, and finally the results of the endeavor which feeds back to the motivation stage. They show how this structure can be used to map different barriers of energy efficiency to the four stages and thereby identify potential chokepoints.

\section{Figure 3: Framework Approaches for Combined Behavioral Analyses}

\section{Energy Cultures Framework}

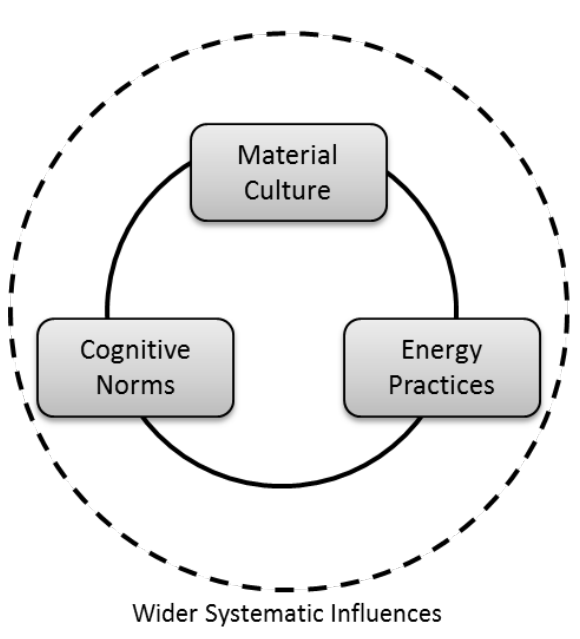

Source: based on Stephenson et al. (2010)

\section{UK ‘Diamond’ Framework}

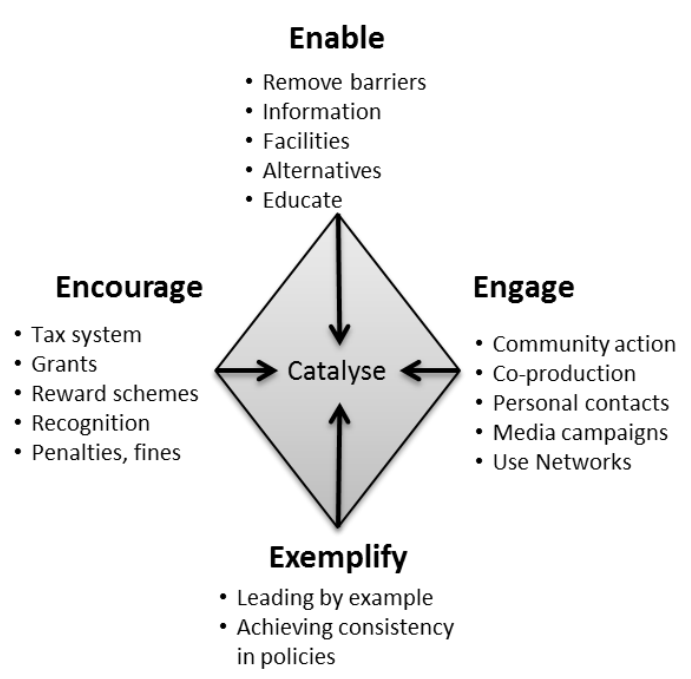

Source: based on Fudge and Peters (2011) 
Those examples can help to structure the first step of an interdisciplinary collaboration and help to identify where interventions may provide the best benefits. The second step will then be to actually design those interventions. Again the frameworks can help to already shape rough characteristics, e.g. whether the identified intervention is part of the 'Enable' or the 'Exemplify' cluster of the Diamond model. Nevertheless, this dimension of the energy consumption discussion passes over into the field of governance and political economy. This field is basically by definition a socio-economic research area and already draws on a large body of experience from a multitude of different aspects tackled in the last decades (if not centuries).

Achieving a sustainable energy system with consumer induced changes in energy consumption as a major element of the transition will require the steering of multiple actors and the cooperation among different organization at different levels of society. Governance in this sense basically refers to steering different actors within their different settings for achieving coordinated actions (“collective action”). But there is little research and little practical knowledge on the relation between change of energy consumption patterns and their according implications on governance structures. However, as observable in real world politics it is reasonable to assume that existing governance structures are not well-suited for implementing change regarding the energy consumption. Current governance structures pursue for example economic and societal development, environmental protection, and energy consumption often as separate topics addressed in specific policy fields. A fully integrated approach, as stipulated by sustainable energy transformation, will most likely require different governance structures. Moreover, many scholars argue for a sort of paradigm change in governance pleading for "adaptive management” oriented strategies taking uncertainty into account (cf. Armitage et al. 2009, Pahl-Wostl 2009, Olsson et al. 2004). Another issue in the wider context of steering strategies could also be the diffusion of policies and/or ideas between institutions and actors (e.g. Strebel, 2011). Also the role of actors is often regarded different in economics and social science providing further potential links for an exchange of ideas; i.e. as already indicated in the Section 4 the role of a regulator in energy markets is viewed in broader context by social science seeing potential for a much more pro-active role due to its intermediate position between supply and demand.

A major difficulty will be to identify and transfer existing governance concepts into the specific energy context. A common understanding and potential improvement and extensions of the underlying theoretic framework is necessary but it will be the transfer of energy demand governance concepts into the real world that will make the difference. Although, this final step is beyond the task of research and has to be carried out by political and social actors the current experiences with political processes shows that a large fraction of those decision are backed up by quantitative research, be it economic models or social field experiments. This is also important due to the large divergences between regions and countries in economic, social and natural/environmental characteristics.

(Field) experiments and observational case studies are certainly one promising field for socioeconomic collaborations. Direct actor observation and interaction has already been a main field for social science and besides classical empirical studies also experiments are becoming increasingly 
important within economics as well (particular in behavioral economics). Joint projects could for example cover the analysis and quantification of newly developed interventions instruments on the end consumer level or the functionality of governance structures on different administrative levels (i.e. community, local or federal level).

Similarly, economic modeling provides a promising field for collaborations. As economic models have become an essential element of ex-ante policy evaluation it is crucial to transfer insights from other fields into those models to improve their validity. Mundaca et al. (2010) provide an overview on different model frameworks with regard to energy efficiency policies from a multidisciplinary perspective. They identify aspects needed to advance those economic models to cope with the specific problems of energy efficiency, including techno-economic, behavioral and political dimensions that need to be addressed. This process if furthermore supported by the improvements in computational capacities and new model and solver approaches that allow much more complex models.

\section{Conclusion}

The transition of our current energy system towards a sustainable one will be one of the major challenges of this century. The upcoming problems related to this transformation process are grounded in technical, environmental, economic, social and political questions and hence it is necessary to shed light on energy research in a holistic context The energy demand side will be one important pillar of this transformation. To achieve a change on the demand side a multitude of different aspects need to be tackled including the efficiency of markets, performance of business and design of products, but also expectations, choices, behaviors, practices and lifestyles of consumers.

Despite this interdisciplinary nature of the transformation process, a majority of energy demand related research and policies are based on singular disciplinary perspectives. This paper aims to provide a review on the current standing in both economic and social science research on energy demand and efficiency. Due to the importance of individual decisions as well as societal influences on energy demand there is a large overlap between the two disciplines in this research field. We propose three research fields for joint socio-economic approaches to tackle the transformation challenges at hand: a descriptive field addressing the question 'what drives energy demand', a theoretic field addressing the question 'why do consumers behave this way', and an applied field tackling the question 'how (end user) energy consumption can be influenced'.

The three proposed questions can act as guiding cornerstones for combined socioeconomic research. The 'what' aims at improving our understanding of how various political, technical, social and economic drivers define the observed energy demand and how they overlap and influence each other. The 'why' is concerned with the internal and external influences that form the energy related decision processes. Tackling this question will improve our understanding of the central element of energy demand: the consumer. Finally, the insights from those two questions will be combined to tackle the last 'how' question. 
The proposed research fields allow a focused joint approach on specific questions and sub-aspects of the energy demand topic and don't require a common agreement on a fundamental theoretic basis. Therefore, they allow the combination of the respective disciplines strengths. The social science perspective introduces the consumer's motivation and behavior, the attitudes and routines or practices, behavioral patterns, value schemes, social factors, cultural aspects and societal developments in general as aspects for the transformation. Thus, the crucial issue is the necessity of a societal and structural change including lifestyles, consumption and values to tackle the challenge of the reduction of the energy consumption. The economic perspective introduces market performance as criterion and addresses market failures and barriers and evaluates specific policy measures with respect to their ability to address the identified market imperfections. The crucial issue is the improvement of the markets efficiency including resource usage, costs and robustness to cope with (uncertain) future developments.

While the market economic view can roughly be described as striving for efficiency/optimality in terms of resource usage and resulting (social) costs the social science approach can roughly be summarized as striving for change through informed decisions without a specific optimal target to be reached. Although, this may seem incompatible at a first glance we still see potential to combine those two views for specific questions. For example the concept of sufficiency is often regarded as lacking in practical relevance and feasibility from an economic viewpoint as it is typically understood as sacrificing utility for a higher goal which cannot (or at least very hard) be quantified. Mirroring this with the social science viewpoint that does not account sufficiency as sacrifice of utility but as a purposive decision for a specific action with lower energy consumption provides a foothold for a joint approach: assuming consumers are aware of the energy consequences (the derived energy demand concept) and aim for a similar (or even higher) utility/satisfaction/happiness with a lower energy input, the basic welfare logic is actually kept intact and only the objective and decision space is adjusted. Similar bridges between the different approaches of the disciplines can be constructed for other specific topics.

Driven by the important role human decisions and interactions play in the field of energy demand coupling economic, social, psychological and technical perspectives can always be achieved by using the customer and its decisions as central linking hub. Thus, within the ongoing debate on the transformation of our energy systems we expect that the demand side will likely to be the starting point for joint (socio-economic) research. However, as the whole energy supply chain is basically a coupled human-nature system also the production or distribution of energy can benefit from extending singular discipline perspectives by more multi- or interdisciplinary approaches (e.g., see Allemann and Burger, 2012). Finally, achieving a paradigm shift in such a complex system like energy which is basically the backbone of our modern societies and therefore touches nearly every part of our life will require concentrated efforts beyond singular viewpoints. The transformation of the energy system in a whole will only be successful if this multifaceted problem is tackled in a similarly interdisciplinary endeavor. 


\section{References}

Alkire, S. (2005) Briefing Note. Capability and Functionings: Definition \& Justification. Human Development and Capability Association. Boston. Unter: http://www.capabilityapproach.com Eingesehen am: 02.03.2011.

Allcott H., 2009, Rethinking Real Time Electricity Pricing. Working Papers 0915, Massachusetts Institute of Technology, Center for Energy and Environmental Policy Research.

Allcott, H. \& Greenstone, M., 2012. Is There an Energy Efficiency Gap? National Bureau of Economic Research Working Paper Series, No. 17766.

Allemann, S., Burger. P. (2012) Towards a Holistic Representation of Power Systems for Sustainability Assessments. FoNEW Discussion Paper 2012/03

AMACAD - American Academy of Arts and Science, 2011, Beyond Technology - Strengthening Energy Policy through Social Sciences. Cambridge (MA).

Armitage, Derek R./Plummer, Ryan/Berkes, Fikret/Arthur, Robert I./Charles, Anthony T./DavidsonHunt, Iain J. et al. 2009: Adaptive co-management for social-ecological complexity. In: Frontiers in Ecology and the Environment (7)2, pp. 95-102.

Banfi, Silvia, Mehdi Farsi, Massimo Filippini, Martin Jakob (2008) Willingness to pay for energysaving measures in residential buildings, Energy Economics, Volume 30, Issue 2, 503-516

Bin, Shui, Hadi Dowlatabadi (2005) Consumer lifestyle approach to US energy use and the related CO2 emissions, Energy Policy, Volume 33, Issue 2, 197-208

Birch, R., J. Barrett, et al. (2004). Exploring the consumption and related environmental impacts of socio-economic groups within the UK. International Workshop on driving forces of and barriers to sustainable consumption., University of Leeds, UK.

BMWi (2011). Forschung für eine umweltschonende, zuverlässige und bezahlbare Energieversorgung.

Das 6. Energieforschungsprogramm der Bundesregierung. Bundesministerium für Wirtschaft und Technologie, Berlin.

Bohi D, Toman M., 1996, Economics of Energy Security. Norwell, MA: Kluwer Academic Publishers

Brohmann, B., Heinzle, S., Nentwich, J., Offenberger, U., Rennings, K., Schleich, J. and Wüstenhagen, R. (2009) Sustainable energy consumption and individual decisions of consumers review of the literature and research needs. Working Paper 1, Soziale, ökologische und ökonomische Dimension eines nachhaltigen Energiekonsums in Wohngebäuden. Darmstadt, Freiburg, Karlsruhe, Mannheim, St. Gallen.

Brounen, Dirk, Nils Kok, John M. Quigley (2013) Energy literacy, awareness, and conservation behavior of residential households, Energy Economics, Volume 38, 42-50

Brown, M., 2001, Market failures and barriers as a basis for clean energy policies. Energy Policy 29, 1197-1207.

Cabeza, Luisa F., Camila Barreneche, Laia Miró, Josep M. Morera, Esther Bartolí, A. Inés Fernández (2013) Low carbon and low embodied energy materials in buildings: A review, Renewable and Sustainable Energy Reviews, Volume 23, 536-542 
Chai, K. H., \& Yeo, C. (2012). Overcoming energy efficiency barriers through systems approach-a conceptual framework. Energy Policy, 46, 460-472.

Coers, Robin, Mark Sanders (2013) The energy-GDP nexus; addressing an old question with new methods, Energy Economics, Volume 36, 708-715

Cohen, J., Pearlmutter, D. and Schwartz, M. (2010) Lifestyle and energy consumption: a comparison of four collective communities in transition. Energy Efficiency, 3:19-31.

Costa, Dora L., Matthew E. Kahn (2013) Do liberal home owners consume less electricity? A test of the voluntary restraint hypothesis, Economics Letters, Volume 119, Issue 2, 210-212

Daly, H. 1996. Beyond Growth: The Economics of Sustainable Development. Beacon Press: Boston.

Department of Energy and Climate Change, United Kingdom (2012) The Energy Efficiency Strategy: The Energy Efficiency Opportunity in the UK. London.

Dennis, K., 2006, The Compatibility of Economic Theory and Proactive Energy Efficiency Policy. The Electricity Journal 19, 58-73.

DOE - United States Department of Energy, Report of the First Quadrennial Technology Review (Washington, D.C.: U.S. Department of Energy, 2011), 125, http://energy.gov/sites/prod/files/ReportOnTheFirstQTR.pdf.

Dusyk, N., Berkhout, T., Burch, S., Coleman, S. and Robinson, J. (2009) Transformative energy efficiency and conservation: a sustainable development path approach in British Columbia, Canada. Energy Efficiency, 2:387-400.

Filippini, Massimo (2011) Short- and long-run time-of-use price elasticities in Swiss residential electricity demand, Energy Policy, Volume 39, Issue 10, 5811-5817

Fong, W. K., H. Matsumoto, et al. (2007). "Influences of indirect lifestyle aspects and climate on household energy consumption." Journal of Asian Architecture and Building Engineering 6(2): 395- 402.

Fudge, S. and Peters, M. (2011) Behaviour Change in the UK Climate Debate: An Assessment of Responsibility, Agency and Political Dimensions. Sustainability 2011, 3, 789-808; doi:10.3390/su3060789.

Gillingham, K., R. Newell and K. Palmer, 2009, Energy Efficiency Economics and Policy. Annual Review of Resource Economics 1, 597-619.

Greening, L., D. Greene and C. Difiglio, 2000, Energy efficiency and consumption - the rebound effect - a survey. Energy Policy 28, 389-401.

Gynther, L., Mikkonen, I. and Smits, A. (2011) Evaluation of European energy behavioral change programms. Energy Efficiency, DOI 10.1007/s12053-011-9115-9.

Heidbrink, L. und Reidel, J. (2011) Nachhaltiger Konsum durch politische Selbstbindung. GAiA Ökologische Perspektiven für Wissenschaft und Gesellschaft, 20/3. S. 152-156.

Herring, H. and R. Roy, 2007, Technological innovation, energy efficient design and the rebound effect. Technovation 27, 194-203 
International Energy Agency (IEA), 2007, Mind the Gap Quantifying Principal-Agent Problems in Energy Efficiency.

Jackson, T. (2006) Challenges for Sustainable Consumption Policy. In: Jackson, Tim (Ed.) The Earthscan Reader in Sustainable Consumption, p. 109-128. Earthscan, London \& Sterling (VA).

Jaffe, A. and Stavins R., 1994, The energy efficiency gap. Energy Policy 22, 904-810.

Jaffe A., Newell R., Stavins R. 2004, The Economics of Energy Efficiency. In Encyclopedia of Energy, ed. C Cleveland, 79-90.

Jaffe A., Newell R., Stavins R. 2005, A Tale of Two Market Failures: Technology and Environmental Policy. Ecological Economics 54, 164-74.

Jonsson, D., Gustaffson, S., Wangel, J., Höjer, M., Lundqvist, P. and Svane, Ö. (2011) Energy at your service: highlighting energy usage systems in the context of energy efficiency analysis. Energy Efficiency, 4:355-369.

Joskow P, Marron D, 1992, What Does a Negawatt Really Cost? Evidence from Utility Conservation Programs. The Energy Journal 13, 41-74.

Joskow P., Tirole J., 2006, Retail electricity competition. RAND Journal of Economics 37(4), 799815.

Kahn, Matthew E. (2007) Do greens drive Hummers or hybrids? Environmental ideology as a determinant of consumer choice, Journal of Environmental Economics and Management, Volume 54, Issue 2, 129-145

Kang, Na Na, Sung Heui Cho, Jeong Tai Kim (2012) The energy-saving effects of apartment residents' awareness and behavior, Energy and Buildings, Volume 46, 112-122

Kavousian, Amir, Ram Rajagopal, Martin Fischer (2013) Determinants of residential electricity consumption: Using smart meter data to examine the effect of climate, building characteristics, appliance stock, and occupants' behavior, Energy, Volume 55, 184-194

Korsunova, A. (2010). Encouraging Energy Conservation with 'No Hard Feelings'. A Two-part Analysis of Communication between Energy Companies and Finnish Households. Jyväskylä Studies in Buisness and Economics, Volume 95. Jyväskylä, Finland.

Kurz, T. (2002) The Psychology of Environmentally Sustainable Behaviour: Fitting Together Pieces of Puzzles. Analysis of Social Issues and Public Policy 2 (1), 257-278.

Lawson, R., \& Williams, J. (2012). Understanding energy cultures. In conference of the Australian and New Zealand Marketing Academy (pp. 3-5).

Lerch, A. (1995). Der Einsatz ökonomischer Instrumente beim Übergang zu einer nachhaltigen Energieversorgung. In: Nutzinger, H.G. (Hrsg.) Nachhaltige Wirtschaftsweise und Energieversorgung. Konzepte, Bedingungen, Ansatzpunkte. Metropolis Verlag, Marburg.

Lijesen, Mark G. (2007) The real-time price elasticity of electricity, Energy Economics, Volume 29, Issue 2, 249-258

Linares, P. and X. Labandeira, 2010Energy Efficiency Economics and Policy. Journal of Economic Surveys 24, 573-592. 
Linz, M. (2006) Was wird dann aus der Wirtschaft? Über Suffizienz, Wirtschaftswachstum und Arbeitslosigkeit. Wuppertal Papers, Nr. 157. Wuppertal Institut, Wuppertal. ISSN 0949-5266.

Linz, M. (2004) Weder Mangel noch Übermaß. Über Suffizienz und Suffizienzforschung. Wuppertal Papers, Nr. 145. Wuppertal Institut, Wuppertal. ISSN 09495266.

Lutzenhiser, L. and B. Hackett (1993). "Social-stratification and environmental degradation understanding household CO2 production" Social Problems 40(1): 50-73.

Mont, O. and Power, K. (2009) Understanding factors that shape consumption. European Topic Centre on Sustainable Consumption and Production, Copenhagen (Denmark).

Muench, Stefan, Edeltraud Guenther (2013) A systematic review of bioenergy life cycle assessments, Applied Energy, Volume 112, 257-273

Mundaca, L., Neij, L., Worrel, E. und McNeil, M. (2010). Evaluating Energy Efficiency Policies with Energy-Economy Models. Annual Review of Environment and Resources. Vol. 35. S. 305-344.

Olsson, Per/Folke, Carl/Berkes, Fikret 2004: Adaptive Comanagement for Building Resilience in Social-Ecological Systems. In: Environmental Management, (34)1, pp. 75-90.

Ortner, S. 1999, Thick resistance: Death and cultural construction of agency in Himalaya mountaineering. In: Ortner, S. (Ed.) The fate of 'culture': Geertz and beyond. Berkeley: University of California Press.

Pahl-Wostl, C. 2009: A conceptual framework for analyzing adaptive capacity and multi-level learning processes in resource governance regimes. Global Environmental Change: Human and Policy Dimensions 19 (3), pp. 354-365.

Popp D, Newell R, Jaffe A, 2010, Energy, the Environment, and Technological Change, Handbook of the Economics of Innovation 2, 873-937.

Pindyck R., 1991, Irreversibility, uncertainty, and investment. Journal of Economic Literature 29(3), 1110-48.

Princen, T. (2006) Consumption and Its Externalities: Where Economy Meets Ecology. In: Jackson, Tim (Ed.) The Earthscan Reader in Sustainable Consumption, p. 50-66. Earthscan, London \& Sterling (VA).

Pyrko, J. and Darby, S. (2011) Conditions of energy efficient behavior - a comparative study between Sweden and the UK. Energy Efficiency, 4:393-408:

Reiss, P. and M. White, 2008, What changes energy consumption? Prices and public pressures. Rand Journal of Economics 39, 636-663.

Reusswig, F., Gerlinger K. and Edenhofer, O. (2003) Lebensstile und globaler Energieverbrauch Analyse und Strategieansätze zu einer nachhaltigen Energiestruktur. Externe Expertise für das WBGU-Hauptgutachten 2003 "Welt im Wandel: Energiewende zur Nachhaltigkeit". Berlin, Heidelberg.

Sanquist, Thomas F., Heather Orr, Bin Shui, Alvah C. Bittner (2012) Lifestyle factors in U.S. residential electricity consumption, Energy Policy, Volume 42, 354-364 
Sanstad A., Howarth R., 1994, Consumer Rationality and Energy Efficiency. Proceedings of the 1994 Summer Study on Energy Efficiency in Buildings, Berkeley, CA.

Savitz, M. (2009). Expanding Opportunities for Energy Efficiency. Editor's Note. The Bridge Linking Engeneering and Society. Vol. 39, Nr. 2. S. 3-4.

Schipper, L. (1996). Life-styles and the environment: The case of energy. Daedalus, 125(3), 113-138.

Shogren J, Taylor L, 2008, On Behavioral-Environmental Economics. Review of Environmental Economics and Policy 2, 26-44.

Shove, Elizabeth (2006) Efficiency and Consumption: Technology and Practice. In: Jackson, Tim

(Ed.) The Earthscan Reader in Sustainable Consumption, p. 293-304. Earthscan, London \& Sterling (VA).

Sorrell, S., 2007, The Rebound Effect: an assessment of the evidence for economy-wide energy savings from improved energy efficiency, UK Energy Research Centre, report produced by the Sussex Energy Group

Sorrell, S., J. Dimitropoulos and M. Sommerville, 2009, Empirical estimates of the direct rebound effect: A review. Energy Policy 37, 1356-1371.

Stengel, O. (2011) Weniger ist schwer. Barrieren in der Umsetzung suffizienter Lebensstile - und wie wir sie überwinden können. GAIA 20/1, 26-30.

Stephenson, J., Barton, B., Carrington, G., Gnoth, D., Lawson, R., \& Thorsnes, P. (2010). Energy cultures: A framework for understanding energy behaviours. Energy Policy, 38(10), 6120-6129.

Strebel, F. (2011). Inter-governmental institutions as promoters of energy policy diffusion in a federal setting. Energy Policy, 39(1), 467-476.

Sweeney, J. C., Kresling, J., Webb, D., Soutar, G. N., \& Mazzarol, T. (2013). Energy saving behaviours: Development of a practice-based model. Energy Policy.

Swiss Academies of Sciences (2012). Zukunft Stromversorgung Schweiz. Positionspaper der Akademien der Wissenschaften Schweiz, Bern, Switzerland.

Tietenberg, T., 2009, Reflections-Energy Efficiency Policy: Pipe Dream or Pipeline to the Future? Review of Environmental Economics and Policy 3, 304-320.

Tversky A, 1972, Elimination by Aspects: A Theory of Choice. Psychological Review 79, 281-99.

van den Bergh, J., 2011, Industrial energy conservation, rebound effects and public policy, UN Development policy, statistics and research branch, Working Paper 12/2011.

Weber, C. and Perrels, A. (2000) Modelling lifestyle effects on energy demand and related emissions. Energy Policy (2000) Nr. 28, S. 549-566.

Wiedmann, Thomas (2009) A first empirical comparison of energy Footprints embodied in trade MRIO versus PLUM, Ecological Economics, Volume 68, Issue 7, 1975-1990

Wilhite, H. 2008, New Thinking on the agentive relationship between end-use technologies and energy-using practices. Energy Efficiency 1:121-130.

Wilson, C. and Dowlatabadi, H. (2007) Models of Decision Making and Residential Energy Use. Annual Review of Environment and Resources, 32:169-203. 
Wolak F. 2006, Residential Customer Response to Real-Time Pricing: The Anaheim Critical- Peak Pricing Experiment. CSEM Working Paper 151, Berkeley, CA.

Wolak, Frank A. 2011, Do Residential Customers Respond to Hourly Prices? Evidence from a Dynamic Pricing Experiment. American Economic Review 101(3), 83-87.

Wei, Y. M., L. C. Liu, et al. (2007). The impact of lifestyle on energy use and CO2 emission: An empirical analysis of China's residents. Energy Policy 35(1): 247-257.

Wyatt, Peter (2013) A dwelling-level investigation into the physical and socio-economic drivers of domestic energy consumption in England, Energy Policy, Volume 60, 540-549

Yun, Geun Young, Koen Steemers, Behavioural (2011) physical and socio-economic factors in household cooling energy consumption, Applied Energy, Volume 88, Issue 6, 2191-2200 